\title{
Could Statin Use Be Associated with Reduced Recurrence Rates following Coiling in Ruptured Intracranial Aneurysms?
}

\author{
(D)W. Brinjikji, V. Shahi, H.J. Cloft, DG. Lanzino, D.F. Kallmes, and R. Kadirvel
}

\begin{abstract}
BACKGROUND AND PURPOSE: A number of studies have examined the role of matrix metalloproteinases in aneurysm healing following endovascular coiling. Because ruptured aneurysms are known to express higher levels of matrix metalloproteinases, we hypothesized that patients with subarachnoid hemorrhage who were on a statin at the time of coil embolization would have lower aneurysm recanalization and retreatment rates than patients not on statins.
\end{abstract}

MATERIALS AND METHODS: We performed a retrospective chart review of patients who underwent intrasaccular coil embolization of ruptured intracranial aneurysms of $\leq 10 \mathrm{~mm}$ with at least 6 months of imaging follow-up. Patients were separated into 2 groups: 1) those on an oral statin medication at the time of coiling, and 2) those who were not. Outcomes studied were aneurysm recurrence and aneurysm retreatment after endovascular coiling. Student $t$ and $\chi^{2}$ tests were used for statistical significance of differences between groups.

RESULTS: One hundred thirty-two patients with 132 ruptured aneurysms were included in our study. Sixteen were on statins (12.1\%) and 116 were not (87.9\%). The recurrence rate was $6.3 \%$ in the statin group $(1 / 16)$ and $36.2 \%$ in the nonstatin group $(42 / 107)(P=.02)$. Unplanned retreatment rates were $6.3 \%(1 / 16)$ for the statin group and $25.9 \%(30 / 116)$ for the nonstatin group $(P=.08)$.

CONCLUSIONS: Statins were associated with a lower rate of aneurysm recurrence following endovascular coiling of small- and mediumsized ruptured aneurysms in this small retrospective study. Further studies are needed to confirm this finding to determine whether statins can be used to reduce recurrence rates in these aneurysms.

ABBREVIATION: MMP = matrix metalloproteinase

A pproximately $20 \%$ of patients undergoing endovascular coiling of intracranial aneurysms have an aneurysm recurrence, and $10 \%$ require retreatment of the coiled aneurysm. ${ }^{1}$ Given the risk of morbidity and mortality associated with retreatment, considerable research has been dedicated to determine methods to reduce the rate of aneurysm recurrence and retreatment. Statin medications are commonly prescribed and have been shown to have a number of beneficial health effects, including reducing the risk of cardiovascular disease and stroke. Statins have been found to stimulate production of extracellular matrix and chemotactic migration and mobiliza-

Received January 16, 2015; accepted after revision April 12.

From the Department of Radiology (W.B., H.J.C., D.F.K., R.K.), Mayo Medical School (V.S.), and Department of Neurosurgery (G.L.), Mayo Clinic, Rochester, Minnesota. This work was supported by the National Institutes of Health (grant NS076491). Please address correspondence to Waleed Brinjikji, MD, Department of Radiology, Mayo Clinic, OL 1-115, 200 SW First St, Rochester, MN 55905; e-mail: brinjikji. waleed@mayo.edu; @WBrinjikji

-- Indicates open access to non-subscribers at www.ajnr.org

http://dx.doi.org/10.3174/ajnr.A4422 tion of endothelial and mesenchymal progenitor cells and stromal osteoblasts, factors important to aneurysm healing. ${ }^{2-5}$ Statins also inhibit chemotaxis of proinflammatory cells such as macrophages by inhibiting expression of adhesion molecules and decreasing macrophage expression of matrix metalloproteinases (MMPs). ${ }^{6}$ MMPs are molecules that have been shown to promote recanalization of arteries and aneurysms following endovascular embolization. ${ }^{7}$

Because statins stimulate cellular and molecular pathways known to be helpful for aneurysm healing and inhibit the expression of MMPs, molecules thought to contribute to aneurysm recanalization following endovascular coiling, it would be interesting to study the effect of statins on aneurysm recanalization and retreatment rates. We retrospectively reviewed a large series of ruptured intracranial aneurysms treated with endovascular coiling and compared the rates of aneurysm recanalization and retreatment among patients who were taking statins at the time of treatment and those who were not. We chose to specifically study ruptured aneurysms because these aneurysms have high recanalization rates and have been shown 
to highly express MMPs, molecules that are inhibited by statin medications. $^{8}$

\section{MATERIALS AND METHODS Patient Selection}

Following institutional review board approval, we conducted a retrospective chart review of all patients who underwent endovascular treatment of ruptured intracranial aneurysms from January 2005 to December 2013. Inclusion criteria were the following: 1) patients receiving intrasaccular coil embolization of an intracranial aneurysm with a maximum diameter of $\leq 10 \mathrm{~mm}, 2$ ) having follow-up imaging with either digital subtraction angiography or MR angiography at least 6 months later, and 3) having a recording of a medical list from the time of presentation at aneurysm rupture. Patients who did not meet all 3 of these criteria were excluded from the analysis.

\section{Baseline Characteristics}

Patients were then stratified into 2 groups: 1) patients on statin medications, and 2) those not on statin medications. Use of statin medications was determined from the patient's medical chart from the time of admission for subarachnoid hemorrhage. Discharge notes were searched to ensure that the patient was not taken off the statin on hospital discharge. Thus, all patients in the statin group were on statins at the time of rupture and during the follow-up period. No patients were started on statins at the time of aneurysm rupture or at discharge. In addition to statin use, we obtained the following information: type and dose of statin, age, sex, comorbidities (hypertension, diabetes mellitus, and current smoking), aneurysm location, aneurysm maximum size, initial degree of occlusion, and use of balloon assistance. Current smokers were defined as patients who were smoking at the time of aneurysm rupture and continued to smoke on follow-up.

\section{Outcomes}

The 2 primary outcomes of this study were aneurysm recurrence and unplanned aneurysm retreatment following endovascular treatment. Initial aneurysm occlusion was categorized on the basis of the Raymond scale into the following groups: 1) residual aneurysm, 2) residual neck, and 3) complete occlusion. Follow-up aneurysm occlusion was categorized into 2 outcomes: 1 ) stable occlusion, and 2) aneurysm recurrence defined as coil compaction and/or recanalization. Retreatments were categorized as unplanned and planned-staged. A retreatment was considered planned-staged if the treating team mentioned in the operative note or follow-up clinical notes that further treatment was recommended to improve aneurysm occlusion (ie, planned coiling of an aneurysm followed by Pipeline Embolization Device [Covidien, Irvine, California] placement). Planned-staged retreatments were excluded from our analysis.

\section{Statistical Analysis}

Continuous variables were presented as mean (SD), and categorical variables, as frequency (percentage). Student $t$ and $\chi^{2}$ tests were used for statistical significance in aneurysm recurrence and/or retreatment in relation to patient statin use. We also performed a multivariate logistic regression analysis to determine whether statin use was independently associated with recanalization and retreatment. Any baseline variables that were significantly different between the 2 groups were included in this model.

\section{RESULTS}

\section{Baseline Characteristics}

When we considered patients with ruptured aneurysms of $\leq 10$ $\mathrm{mm}, 16$ patients were on statin medications at the time of treatment and 116 patients were not. The mean age of the statin group was higher than that of the nonstatin group (70.2 versus 57.0 years, $P<.0001)$. Mean aneurysm size was similar between groups (5.4 versus $5.6 \mathrm{~mm}, P=.63$ ). Baseline occlusion status $(P=.51)$ and use of balloon assistance were similar between groups $(P=.31)$. There were similar rates of hypertension $(P=$ $.59)$, diabetes mellitus $(P=.20)$, and smoking $(P=.19)$ between groups. Mean follow-up was 23.4 months for the statin group and 25.1 months for the nonstatin group $(P=.59)$.

Among patients in the statin group, the most common statin medication used was simvastatin (6 patients; dose, 20-40 mg), followed by atorvastatin ( 5 patients; dose, $10-20 \mathrm{mg}$ ), rosuvastatin (3 patients; dose, 5-20 mg), and pravastatin (2 patients; dose, $20-80 \mathrm{mg}$ ). All patients were on statin therapy for the duration of their follow-up (25-96 months). The indication for statin therapy was hyperlipidemia in all cases.

\section{Outcomes}

Recurrence rates were significantly lower in the statin group than in the nonstatin group. Recurrence rates were $6.3 \%(1 / 16)$ for the statin group and $36.2 \%(41 / 116)$ for the nonstatin group $(P=$ $.02)$. There was a trend toward lower retreatment rates in the statin group. Unplanned retreatment rates were 6.3\% (1/16) for the statin group and $25.9 \%(30 / 116)$ for the nonstatin group $(P=$ $.08)$. Among patients in the nonstatin group, 16 were recoiled, 5 underwent flow-diverter treatment, and 9 underwent clipping. One patient in the statin group was retreated with a flow diverter. These data are summarized in the Table.

The only baseline characteristic that differed between the statin and nonstatin groups was mean age. When we considered patients with ruptured aneurysms of $\leq 10 \mathrm{~mm}$ and adjusted for age, statin use was associated with significantly lower odds of recurrence $(\mathrm{OR}=0.13 ; 95 \% \mathrm{CI}, 0.01-0.72 ; P=.016)$ and a nonstatistically significant lower odds of retreatment $(\mathrm{OR}=0.29$; 95\% CI, 0.01-1.55; $P=.16$ ).

\section{DISCUSSION}

Our small, retrospective study demonstrated that patients with ruptured aneurysms of $\leq 10 \mathrm{~mm}$ who were on a statin at the time of aneurysm treatment had lower rates of aneurysm recurrence and had a trend toward lower retreatment rates compared with those who were not on a statin. These findings are important because they suggest that statin use may represent a low-cost and efficacious therapy in reducing recurrence rates in some patients with ruptured aneurysms. However, these results need to be confirmed in future, larger studies before they can be applied in routine clinical practice.

We chose to specifically study the recanalization rates of ruptured aneurysms undergoing endovascular coiling because 
Baseline characteristics and recurrence and retreatment rates: ruptured aneurysms of $\leq 10 \mathrm{~mm}$

\begin{tabular}{|c|c|c|c|}
\hline & Statin Group & Nonstatin Group & $P$ Value \\
\hline No. & 16 & 116 & - \\
\hline Mean age (SD) (yr) & $70.2(9.0)$ & $57.0(11.7)$ & $<.0001$ \\
\hline No. (\%) women & $12(75.0)$ & $77(66.4)$ & .58 \\
\hline No. (\%) hypertension & $10(62.5)$ & $61(52.6)$ & .59 \\
\hline No. $(\%)$ diabetes & $3(18.8)$ & $10(8.6)$ & .20 \\
\hline No. (\%) current smoker & $3(18.8)$ & $41(35.3)$ & .19 \\
\hline \multicolumn{4}{|l|}{ Aneurysm location } \\
\hline ICA (No.) (\%) & 6 & 41 & .88 \\
\hline ACA/AcomA (No.) (\%) & 9 & 50 & \\
\hline MCA (No.) (\%) & 0 & 7 & \\
\hline VBA (No.) (\%) & 1 & 16 & \\
\hline Other (No.) (\%) & 0 & 2 & \\
\hline Mean size (SD) (mm) & $5.4(1.8)$ & $5.6(2.0)$ & .63 \\
\hline \multicolumn{4}{|l|}{ Initial occlusion } \\
\hline Complete & $8(5.0)$ & $60(51.7)$ & .51 \\
\hline Residual neck & $6(37.5)$ & $50(43.1)$ & \\
\hline Residual aneurysm & $2(12.5)$ & $6(5.2)^{\prime}$ & \\
\hline Balloon assistance & $4(25.0)$ & 18 (15.5) & .31 \\
\hline Mean follow-up (months) & $23.4(14.4)$ & $25.1(25.4)$ & .59 \\
\hline No. (\%) recurrence & $1(6.3)$ & $42(36.2)$ & .02 \\
\hline No. (\%) retreatment & $1(6.3)$ & $30(25.9)$ & .08 \\
\hline
\end{tabular}

Note:-ACA indicates anterior cerebral artery; AcomA, anterior communicating artery; VBA, vertebrobasilar arteries; -, no $P$ value.

MMPs are expressed at significantly higher levels in ruptured compared with unruptured aneurysms. ${ }^{8-10} \mathrm{MMPs}$, specifically MMP-2 and MMP-9, are proteases that are thought to play a role in aneurysm formation, growth, rupture, and recanalization. ${ }^{11-14}$ Statins are potent inhibitors of MMP-2 and MMP-9 formation and expression. ${ }^{15-18}$ We hypothesized that by inhibiting MMPs early in the healing process, statins can prevent any further growth of the aneurysm, thus reducing recurrence rates. This hypothesis is supported by work from Hasan et al, ${ }^{19}$ who demonstrated that aneurysm sac growth, not coil compaction, is the primary mechanism associated with postcoiling aneurysm recurrence. In addition, statins likely enhance many other facets of the aneurysm healing process such as cellular infiltration of the aneurysm dome, deposition of extracellular matrix, and endothelialization of the aneurysm neck. ${ }^{5,15,20}$ Statins upregulate expression of transforming growth factor $\beta$ and bone morphogenetic protein 2, factors important in stimulating migration of osteoblasts and mesenchymal progenitor cells to the aneurysm dome. ${ }^{21}$

There are some other, previously reported preclinical data to suggest that statins could improve aneurysm healing following endovascular treatment of intracranial aneurysms. One previous study comparing statin-coated coils with bare metal coils in the coil embolization of rat aneurysms demonstrated that aneurysms treated with statin-covered coils had improved aneurysm occlusion due to increased tissue organization around the coils and increased collagen deposition in the aneurysm dome. In addition, this same previous study demonstrated increased endothelialization of the aneurysm neck in statin-covered-coil-treated aneurysms compared with non-statin-covered-coiled aneurysms. $^{22}$ A number of previous clinical studies of patients receiving endovascular aortic aneurysm repair have demonstrated that statin therapy can promote aneurysm sac regression and healing. A study by Raux et $\mathrm{al}^{23}$ demonstrated that patients undergoing endovascular aortic aneurysm repair who were on statins had a significantly higher rate of aneurysm sac regression compared with their non-statin-using counterparts.
These results were confirmed by a later study performed by Gray et $\mathrm{al},{ }^{24}$ who demonstrated that statin use was independently associated with aneurysm sac regression following endovascular aortic aneurysm repair.

\section{Limitations}

Our study has limitations. First, we included only patients with aneurysms of $\leq 10 \mathrm{~mm}$. We excluded patients with large and giant aneurysms because these patients had much higher recanalization rates than those with small- and medium-sized aneurysms due to difficulties in achieving high packing attenuation. ${ }^{25}$ Thus, inclusion of large aneurysms may mask the benefit isolated to small- and medium-sized ones. Our study included only ruptured aneurysms because they have a different biology from unruptured aneurysms as evidenced by elevated recurrence rates in many series. ${ }^{26}$ In our study, only 16 patients were on statin medication. This low number may have limited our ability to detect differences between the statin and nonstatin groups in aneurysm retreatment rates. In addition, the low number of statin-using patients in our study makes our conclusions unreliable because if only 1 additional patient had a recurrence in the statin group, statistical significance would be lost. Another limitation is that patients were on various statin agents and on various doses. There are differences in statin efficacy by type and dose.

Given the small size and limitations, our study should not serve to alter clinical management of patients with ruptured aneurysms. Ultimately, this study sought to determine whether systemic statin therapy warrants further study as a potential way to reduce aneurysm recanalization for patients with ruptured aneurysms. Future studies, including animal studies examining the effects of statins on the cellular response to endovascular coiling, large retrospective reviews combining data with multiple centers, and prospective clinical trials studying the impact of statins on angiographic outcomes of patients with ruptured intracranial aneurysms are needed to confirm these findings. 


\section{CONCLUSIONS}

Our study found that patients with ruptured aneurysms of $\leq 10$ $\mathrm{mm}$ who were on statins had significantly lower aneurysm recanalization rates than those who were not on statins. In addition, there was a trend toward lower retreatment rates in the statin group. These results suggest that the role of systemic statin therapy in reducing aneurysm recanalization rates in patients with ruptured aneurysms undergoing coiling should be further studied. More data from preclinical and retrospective and prospective clinical studies are needed to determine whether statins do, in fact, reduce aneurysm recanalization in the ruptured aneurysm population.

Disclosures: Waleed Brinjikji—RELATED: Grant: Brain Aneurysm Foundation, ${ }^{*}$ Comments: Dr Brinjikji's effort was supported by a grant from the Brain Aneurysm Foundation. Giuseppe Lanzino-UNRELATED: Consultancy: ev3/Covidien.* David F. Kallmes_UNRELATED: Board Membership: GE Healthcare, Comments: Advisory Board, Cost Effectiveness; Consultancy: ev3, ${ }^{*}$ Comments: planning and implementing clinical trials; Grants/Grants Pending: MicroVention, ${ }^{*}$ Sequent, ${ }^{*}$ Surmodics, ${ }^{*}$ Codman, ${ }^{*}$ Benvenue Medical, ${ }^{*}$ University of Virginia, ${ }^{*}$ NeuroSigma, ${ }^{*}$ Comments: preclinical research and planning and implementing clinical trials; Royalties: University of Virginia Patent Foundation, Comments: spine fusion. Ramanathan KadirvelRELATED: Grant: National Institutes of Health NS076491.* *Money paid to the institution.

\section{REFERENCES}

1. Ferns SP, Sprengers ME, van Rooij WJ, et al. Coiling of intracranial aneurysms: a systematic review on initial occlusion and reopening and retreatment rates. Stroke 2009;40:e523-529 CrossRef Medline

2. Landmesser U, Engberding N, Bahlmann FH, et al. Statin-induced improvement of endothelial progenitor cell mobilization, myocardial neovascularization, left ventricular function, and survival after experimental myocardial infarction requires endothelial nitric oxide synthase. Circulation 2004;110:1933-39 CrossRef Medline

3. Song L, Yang YJ, Dong QT, et al. Atorvastatin enhance efficacy of mesenchymal stem cells treatment for swine myocardial infarction via activation of nitric oxide synthase. PLoS One 2013;8:e65702 CrossRef Medline

4. Sonobe M, Hattori K, Tomita N, et al. Stimulatory effects of statins on bone marrow-derived mesenchymal stem cells: study of a new therapeutic agent for fracture. Biomed Mater Eng 2005;15:261-67 Medline

5. Brinjikji W, Kallmes DF, Kadirvel R. Mechanisms of healing in coiled intracranial aneurysms: a review of the literature. AJNR Am J Neuroradiol 2015;36:1216-22 CrossRef Medline

6. Blanco-Colio LM, Tuñón J, Martin-Ventura JL, et al. Anti-inflammatory and immunomodulatory effects of statins. Kidney Int 2003; 63:12-23 CrossRef Medline

7. Bouzeghrane F, Darsaut T, Salazkin I, et al. Matrix metalloproteinase-9 may play a role in recanalization and recurrence after therapeutic embolization of aneurysms or arteries. J Vasc Interv Radiol 2007;18:1271-79 CrossRef Medline

8. Marchese E, Vignati A, Albanese A, et al. Comparative evaluation of genome-wide gene expression profiles in ruptured and unruptured human intracranial aneurysms. J Biol Regul Homeost Agents 2010;24: 185-95 Medline

9. Serra R, Volpentesta G, Gallelli L, et al. Metalloproteinase-9 and neutrophil gelatinase-associated lipocalin plasma and tissue levels evaluation in middle cerebral artery aneurysms. BrJ Neurosurg 2014 May 5. [Epub ahead of print] CrossRef Medline

10. Jin D, Sheng J, Yang X, et al. Matrix metalloproteinases and tissue inhibitors of metalloproteinases expression in human cerebral ruptured and unruptured aneurysm. Surg Neurol 2007;68(suppl 2): S11-16; discussion S16 CrossRef Medline

11. Kim SC, Singh M, Huang J, et al. Matrix metalloproteinase-9 in cerebral aneurysms. Neurosurgery 1997;41:642-46; discussion 646-47 Medline

12. Razavian M, Zhang J, Nie L, et al. Molecular imaging of matrix metalloproteinase activation to predict murine aneurysm expansion in vivo. J Nucl Med 2010;51:1107-15 CrossRef Medline

13. Aoki T, Kataoka H, Morimoto M, et al. Macrophage-derived matrix metalloproteinase- 2 and -9 promote the progression of cerebral aneurysms in rats. Stroke 2007;38:162-69 CrossRef Medline

14. Pannu H, Kim DH, Guo D, et al. The role of MMP-2 and MMP-9 polymorphisms in sporadic intracranial aneurysms. J Neurosurg 2006;105:418-23 CrossRef Medline

15. Bellosta S, Via D, Canavesi M, et al. HMG-CoA reductase inhibitors reduce MMP-9 secretion by macrophages. Arterioscler Thromb Vasc Biol 1998;18:1671-78 CrossRef Medline

16. Ganné F, Vasse M, Beaudeux JL, et al. Cerivastatin, an inhibitor of HMG-CoA reductase, inhibits urokinase/urokinase-receptor expression and MMP-9 secretion by peripheral blood monocytes: a possible protective mechanism against atherothrombosis. Thromb Haemost 2000;84:680-88 Medline

17. Guo H, Shi Y, Liu L, et al. Rosuvastatin inhibits MMP-2 expression and limits the progression of atherosclerosis in LDLR-deficient mice. Arch Med Res 2009;40:345-51 CrossRef Medline

18. Wong B, Lumma WC, Smith AM, et al. Statins suppress THP-1 cell migration and secretion of matrix metalloproteinase 9 by inhibiting geranylgeranylation. J Leukoc Biol 2001;69:959-62 Medline

19. Hasan DM, Nadareyshvili AI, Hoppe AL, et al. Cerebral aneurysm sac growth as the etiology of recurrence after successful coil embolization. Stroke 2012;43:866-68 CrossRef Medline

20. Luan Z, Chase AJ, Newby AC. Statins inhibit secretion of metalloproteinases-1, $-2,-3$, and -9 from vascular smooth muscle cells and macrophages. Arterioscler Thromb Vasc Biol 2003;23:769-75 CrossRef Medline

21. Nyan M, Miyahara T, Noritake K, et al. Molecular and tissue responses in the healing of rat calvarial defects after local application of simvastatin combined with alpha tricalcium phosphate. JBiomed Mater Res B Appl Biomater 2010;93:65-73 CrossRef Medline

22. Kodama T, Iwata H. Comparison of bare metal and statin-coated coils on rates of intra-aneurysmal tissue organization in a rat model of aneurysm. J Biomed Mater Res B Appl Biomater 2013;101:656-62 CrossRef Medline

23. Raux M, Cochennec F, Becquemin JP. Statin therapy is associated with aneurysm sac regression after endovascular aortic repair. $J$ Vasc Surg 2012;55:1587-92 CrossRef Medline

24. Gray C, Goodman P, O’Malley MK, et al. Statins promote residual aneurysm sac regression following endovascular aortic aneurysm repair. Vasc Endovasc Surg 2014;48:111-15 CrossRef Medline

25. Chalouhi N, Tjoumakaris S, Gonzalez LF, et al. Coiling of large and giant aneurysms: complications and long-term results of 334 cases. AJNR Am J Neuroradiol 2014;35:546-52 CrossRef Medline

26. Crobeddu E, Lanzino G, Kallmes DF, et al. Review of 2 decades of aneurysm-recurrence literature, part 1: reducing recurrence after endovascular coiling. AJNR Am J Neuroradiol 2013;34:266-70 CrossRef Medline 